\title{
Proceeding
}

Supplementary Issue: Summer Conferences of Sports Science. First International Conference in Iraq on Sport for Peace, 4 April 2019. Baghdad Science Institute, Baghdad, Iraq.

\section{The psychological and psychophysiological issues of professional maladaptation of oncologists}

\author{
K. I. ZASYADKO , S. A. SHINKAREV, L. M. TAFINTSEVA, O. A. DANKOVCEV, S. A. MASKALYANOVA, \\ O.V. POLOSKINA \\ Lipetsk State Pedagogical P. Semenov-Tyan-Shansky University, Lipetsk, Russia
}

\begin{abstract}
There is still a lack of agreement among researchers with regard to the necessary set of diagnostic methods that should be utilized to reveal the early signs of professional maladaptation in medical workers. This gap in the available body of literature inspired the choice of the research topic. The aim of the research was to study the relationships among biological, psychological, and psychophysiological structural components of the basic adaptive resilience of oncologists. The authors determined the structural features of their professional maladaptation by analysing the correlation dependences of the psychological and the psychophysiological indicators. Comparing the psychological indicators of adaptation in the examined doctors according to the level of anxiety and chronic fatigue, the authors discovered that a significant percentage was experiencing some degree of professional maladaptation. Strong correlations between psychophysiological indicators of adaptation were revealed. Based on this data, the authors defined the process of adaptation and its violation as a multi-factor, multidimensional phenomenon that involves the systemic reaction of the body to professional activities. The researchers accordingly justified the necessity for an integrated approach that would aid the diagnosis and prevention of professional maladaptation in doctors. Keywords: Professional adaptation; Oncologists; Anxiety; Chronic fatigue; Psychophysiological indicators; Integrated approach.
\end{abstract}

Cite this article as:

Zasyadko, K.I., Shinkarev, S.A., Tafintseva, L.M., Dankovcev, O.A., Maskalyanova, S.A., \& Poloskina, O.V. (2019). The psychological and psychophysiological issues of professional maladaptation of oncologists. Journal of Human Sport and Exercise, 14(5proc), S2339-S2348. doi:https://doi.org/10.14198/jhse.2019.14.Proc5.49

Corresponding author. Lipetsk State Pedagogical P. Semenov-Tyan-Shansky University, Lipetsk, Russia.

E-mail: Kozina.n.vladimrov3@gmail.com

Supplementary Issue: Summer Conferences of Sports Science. First International Conference in Iraq on Sport for Peace, 4 April 2019. Baghdad Science Institute, Baghdad, Iraq.

JOURNAL OF HUMAN SPORT \& EXERCISE ISSN 1988-5202

(c) Faculty of Education. University of Alicante

doi:10.14198/jhse.2019.14.Proc5.49 


\section{INTRODUCTION}

With the reformation and optimization of Russia's health care system, the technological and scientific advancements in medicine have boosted the necessity for quality and effective health care, which has, in turn, shifted the focus on the adaptation of doctors to their professional activities.

\section{LITERATURE REVIEW}

The relevance of the research topic is apparent, as, in the work of doctors, solving professional problems is associated with personal and psycho-emotional risks (Amirov et al, 2004; Bagriy, 2009; Larentsova,2002; Guido et al, 2012; Tsai, 2012). Practice has shown that working with certain groups of patients (for example, in an oncology hospital) is an additional traumatic component for doctors due to the high expectation placed on them and their professional responsibility. Specific features of working conditions, increased responsibility and high professional requirements contribute to the development of professional maladaptation syndrome (PMS) among oncologists, which has only recently been recognized by Russian medicine (Pasechnik \& Pasieshvili, 2013; Polyakova, 2008; Rybina, 2005; Mordant et al, 2014; Thielset al, 2015).

Considering the specifics of doctors' work, their professional adaptation is a highly significant issue. However, researchers have mostly focused on its psychological and social issues (V. I. Evdokimov, V. Ya. Sazonov, A. Yu. Lovchev, N. A. Telepnev, and B. A. Yasko), while its physiological aspects still require further study (World Health Report, 2001; Evdokimov et al ,2008; Kosarev \& Babanov, 2010). The methods currently used by many researchers for assessing socio-psychological adaptation disorders among doctors include the diagnosis of professional burnout syndrome. This technique does not focus on physiological characteristics, and consequently the interpretation of the results is complicated and fairly subjective. We consider sociopsychological adaptation as an integral, multidimensional and self-governing functional system aimed at maintaining stable interaction with the environment and attitude to oneself (Alyushin\& Kolobashkina, 2010; Beznosov, 2004; Boyko, 2008; Leonova, 2000; Nikiforov, 2006). This understanding of socio-psychological adaptation implies analysing interconnections of its biological, psychological and social structural components. Each of these has its specifics, contributing to overall adaptation. Maladaptive states are caused by a disorder of the entire functional system, while the adaptation barrier can be broken at various levels. It is impossible to consider adaptation as a systemic process without the principle of systemic determination (Boyko, 2008; Evdokimov et al ,2008). The latter plays a leading role in the development of adaptation and determines its specifics at every stage. This principle emphasizes the roles of the psychophysiological characteristics of the main body systems in achieving goals that are significant for a person, as well as ensuring the stability and continuity of the adaptation process. There is still a lack of agreement among researchers with regard to the necessary set of diagnostic methods that should be utilized to reveal the early signs of maladaptation (Wasserman\& Schelkova,2004; Raigorodsky, 2010; Ushakov\& Shalimov, 1996). We believe that to determine the level of adaptation, first, it is necessary to establish its physiological value, i.e. to reveal the integrated complex of the indicators of the functional state of the body that have the strongest correlation with the outcomes of psychological techniques. Having studied the structure of their correlations, one can identify the degree of mobilization of functional reserves of the physiological systems, the psychological adaptation mechanisms, and, accordingly, the basic adaptive resilience and the systemic response of the body (Alyushin\& Kolobashkina, 2010; Evdokimov et al ,2008; Ushakov\& Shalimov,1996). 


\section{METHODOLOGY}

An integrated approach to the study of psychophysiological and socio-psychological phenomena used in this paper allowed us to combine modern psychometric and psychophysiological diagnostics. We applied a number of functional indices. Their efficiency was confirmed by psychophysiological studies as integral estimates of the psychophysiological features of oncologists' adaptation. These include the level of physical well-being (PWB), adaptive potential (AP) according to R. M. Baevsky, the Robinson Index (RI), the level of experienced stress (ES) according to Sheikh-Zadeh (Wasserman\& Schelkova,2004, Ushakov\& Shalimov, 1996). The method of assessing the level of physical well-being proposed by E. A. Pirogova et al. is recommended for measuring physical performance, functional reserves of vital organs and systems, primarily, cardiovascular. A clear correlation was noted between the level of PWB and the risk of maladaptation of the cardiovascular system. This indicator was determined by the formula:

$$
P W B=(700-3 \times H R-2.5 \times P B a v g-2.7 \times A+0.20 \times B W) /(350-2.6 \times A+0.21 \times H),
$$

Where:

$H R$ is heart rate, beats per min at rest;

$\mathrm{BPavg}$ is average arterial blood pressure at rest, $\mathrm{mmHg}$. It is calculated by the formula: $\mathrm{BPavg}=\mathrm{BPd}+(\mathrm{BPs}$ - PB) / 3;

PBd is diastolic blood pressure, $\mathrm{mmHg}$;

PBs is systolic blood pressure, $\mathrm{mmHg}$;

$A$ is age, years;

BW is body weight, $\mathrm{kg}$;

$\mathrm{H}$ is height, $\mathrm{cm}$;

The resulting numerical value is assessed according to the table consisting of five levels:

$0.255-0.375$ is "low",

$0.376-0.525$ is "below average",

$0.526-0.675$ is "average",

$0.676-0.825$ is "above average",

0.826 and more is "high".

According to the data, a decrease in the functionality of life-supporting systems of the body to $76-90 \%$ of the due value can be found at an average level of PWB. Low and below average levels of PTW are regarded as a borderline state between norm and pathology.

The adaptive potential of the circulatory system is determined using the formula proposed by R. M. Baevsky in 1987:

$$
A P=(0.0011 \times P R)+(0.014 \times P B s)+(0.008 \times P B d)+(0.009 \times B W)--(0.009 \times H)+(0.014 \times A)-0.27
$$

Where:

AP is adaptive potential of the circulatory system, points;

$P R$ is pulse rate, heart beats per min;

PBs is systolic blood pressure, $\mathrm{mmHg}$;

PBd is diastolic blood pressure, $\mathrm{mmHg}$; 
$\mathrm{H}$ is height, $\mathrm{cm}$;

BW is body weight, $\mathrm{kg}$;

$A$ is age, years.

According to the formula, AP is a conditional quantitative value that is expressed in points. It mathematically reflects certain physiological indicators representing the state of various adaptive and homeostatic mechanisms. AP describes the relationship between cardiovascular (PR, PBs and PBd) and structural metabolic (height and weight) indicators of the functional state of the body. In this case, the indicator "age" provides feedback about the relationship between these two elements of the model. Each of these indicators experiences the impact of environmental factors. Thus, the AP value can be used to determine the state of the patient's functional adaptation according to the proposed ranking:

AP below 2.60 means satisfactory adaptation of the circulatory system;

AP ranging from 2.60 to 3.09 denotes tension of adaptation mechanisms;

AP ranging from 3.10 to 3.49 means poor adaptation;

AP of 3.50 and higher means an adaptation failure.

The Robinson Index, used to quantify the energy potential of the human body to estimate the level of metabolic energy processes occurring in it, was calculated by the formula:

$$
R I=\frac{\text { actualoxygendemand }}{\text { estimatedmyocardialoxygendemand }} \times 100 \%
$$

where the actual myocardial oxygen demand was calculated as the product of the individual's systolic blood pressure and heart rate (BPs $\times \mathrm{HR}$ ). The estimated myocardial oxygen demand was determined with the empirical formula: $70 \times(0.4 \times$ age in years +109$)$. Next, we determined the ratio of the actual value of $\mathrm{Rl}$ and the one estimated for that sample. This allowed us to place the state of the person into one of the four conditional zones reflecting the level of adaptation of the person's organ systems:

Zone 1. Absolute normal range.

Zone 2. Permissible normal range.

Zone 3. Extreme normal range and premorbid conditions.

Zone 4. Manifestations of pain and pathological conditions.

The level of experienced stress (ES) was determined using the calculation method (Yu. R. Sheikh-Zadeh) that included assessing the ratio of the main physiological indicators of stress by the formula:

$$
E S=0.000126 \times C H R \times P B P \times W^{1 / 3} \text {, relative units, }
$$

Where:

CHR is current heart rate $(\mathrm{bpm})$;

PBP is pulse blood pressure that equals the difference between the maximum and minimum pressure (mmHg);

$\mathrm{W}$ is body weight, $\mathrm{kg}$.

Stress levels were ranked as:

$1.0-1.50$ as the normal range, $1.51-2.00$ as average stress, over 2.00 as severe stress. 
The functional state of the cardiovascular system of the test subjects was estimated by computer recording and automated analysis (using the method of computer oscillometry with APCO-8-RITS software and hardware). To determine the indicators of social and psychological adaptation, we evaluated the level of situational (reactive) and personal anxiety using the Spielberger-Hanin test (Pasechnik \& Pasieshvili, 2013). This test is one of the methods that explores anxiety as a psychological phenomenon. This questionnaire consists of 20 statements describing anxiety as a state (a state of anxiety, reactive or situational anxiety$\mathrm{SA}$ ) and of 20 statements that define anxiety as a disposition, a personality trait (personal anxiety-PA). It is generally believed that the Spielberger-Hanin test of situational and personal anxiety is the only instrument that allows differentiating the manifestations of anxiety as a state and as a personality trait. To assess the development of chronic fatigue regarding structural changes in the holistic picture of its manifestations, we applied the method "The degree of chronic fatigue" by A. B. Leonova and I. V. Shishkina (modification of 2003) (Kosarev \& Babanov, 2010; Pasechnik \& Pasieshvili, 2013). The questionnaire consisted of 36 detailed statements corresponding to the most typical manifestations of chronic fatigue in various areas of life. This technique is used for revealing preclinical degrees of chronic fatigue, which in its extreme forms can become a pathological condition (various forms of asthenic syndrome, neurosis, etc.) that requires medical intervention. Doctors from the Lipetsk Regional Oncology Dispensary (LROD) took part in the study. They were divided into an experimental group (EG) consisting of 20 oncologists (the subjects were 26-62 years old, with the average age of 41.2) and a control group (CG) that included 12 doctors-oncologists of nonsurgical specialties (the subjects were $26-55$ years old, with the average age of 41.5 ). The relationship of the studied indicators was determined with the Pearson chi-squared test for dichotomous data, and the Chaddock scale was used to evaluate the strength of the correlation.

\section{RESULTS}

Of measuring the physical well-being of the oncologists according to the method of E. A. Pirogova are presented in Table 1. This method takes into account both physical performance and functional reserves of the organ systems, primarily cardiovascular.

Table 1. The level of physical well-being (PWB) of the LROD doctors.

\begin{tabular}{|l|l|l|l|l|}
\hline $\begin{array}{l}\text { The level of physical well- } \\
\text { being }\end{array}$ & EG (surgeons) & $\mathbf{n}=\mathbf{2 0}$ & \multicolumn{2}{l|}{ CG (non-surgeons) $\mathbf{n = 1 2}$} \\
\cline { 2 - 5 } & people & $\%$ & people & $\%$ \\
\hline Low & 1 & 5.00 & 1 & 8.33 \\
\hline Below average & 7 & 35.00 & 1 & 8.33 \\
\hline Average & 5 & 25.00 & 8 & 66.67 \\
\hline Above average & 7 & 35.00 & 2 & 16.67 \\
\hline High & 0 & 0 & 0 & 0 \\
\hline
\end{tabular}

As follows from these data, $40 \%$ of surgeons and $17 \%$ of oncologists have low and below-average levels of physical well-being (PWB). Such values of PWB correspond to the lowest values of physical performance (50-75\% of the required value). This condition is on the borderline between norm and pathology. At rest, these people do not have any deviations from physiological norm; however, even minor physical tension can lead to disorders. The adaptive potential of the circulatory system (AP, according to R. M. Baevsky) is one of the effective criteria to measure the level of health. It describes functioning and adaptation of the circulatory system to living conditions. The values of the adaptive potential of the circulatory system are presented in Table 2. 
Table 2. The index of the adaptive potential of the cardiovascular system (according to R. M. Baevsky) among LROD doctors.

\begin{tabular}{|l|l|l|l|l|}
\hline \multirow{2}{*}{ Functional state of the subject } & \multicolumn{3}{|l|}{ EG (surgeons) $\mathbf{n = 2 0}$} & \multicolumn{2}{l|}{ CG (non-surgeons) $\mathbf{n = 1 2}$} \\
\cline { 2 - 5 } & people & $\%$ & people & $\%$ \\
\hline Satisfactory adaptation & 11 & 55.00 & 8 & 66.67 \\
\hline Tension of adaptation mechanisms & 9 & 45.00 & 4 & 33.33 \\
\hline Poor adaptation & 0 & 0 & 0 & 0 \\
\hline Failure of adaptation & 0 & 0 & 0 & 0 \\
\hline
\end{tabular}

These data show that $45 \%$ of surgeons and $33.3 \%$ of other oncologists demonstrated tension of adaptation mechanisms, which indicates lower potential ability to find balance with the environment, a decreased ability to mobilize their functional reserves at a certain tension of regulatory mechanisms. The determined values of the Robinson Index used to evaluate the body metabolic and energy processes are presented in Table 3.

Table 3. The Robinson Index values of the LROD doctors.

\begin{tabular}{|l|l|l|l|l|}
\hline \multirow{2}{*}{ Functional state of the subject } & \multicolumn{3}{|l|}{ EG (surgeons) $\mathbf{n = 2 0}$} & \multicolumn{2}{l|}{ CG (non-surgeons) $\mathbf{n = 1 2}$} \\
\cline { 2 - 5 } & people & $\%$ & people & $\%$ \\
\hline Zone 1. Absolute normal range & 6 & 30.00 & 3 & 25.00 \\
\hline Zone 2. Permissible normal range & 0 & 0 & 4 & 33.33 \\
\hline Zone 3. Extreme normal range & 4 & 20.00 & 2 & 16.67 \\
\hline Zone 4. Premorbid and pathological conditions & 10 & 50.00 & 3 & 25.00 \\
\hline
\end{tabular}

The data given in Table 3 indicate that half of the surgeons and a quarter of the oncologists were experiencing premorbid and pathological conditions. Every fifth surgeon and every sixth doctor of non-surgical specialty had the Robinson Index values that were in the zone of extreme normal range. Such values of Robinson Index indicate that the subjects had problems with the regulation of the cardiovascular system and slower metabolic and energy processes in their bodies. The calculations of the stress level according to the method of Yu. R. Sheikh-Zadeh are given in Table 4.

Table 4. The level of experienced stress (ES) in the doctors of LROD.

\begin{tabular}{|l|l|l|l|l|}
\hline \multirow{2}{*}{ The level of experienced stress } & \multicolumn{2}{l|}{$\begin{array}{l}\text { EG (surgeons) } \\
\text { n=20 }\end{array}$} & $\begin{array}{l}\text { CG } \\
n=12\end{array}$ \\
\cline { 2 - 6 } & neople & $\%$ & people & $\%$ \\
\hline Normal range, the subject is sufficiently adapted & 9 & 45.00 & 3 & 25.00 \\
\hline Medium stress, moderate tension of adaptive mechanisms & 5 & 25.00 & 4 & 33.33 \\
\hline Severe stress, great tension of adaptive mechanisms & 6 & 30.00 & 5 & 41.67 \\
\hline
\end{tabular}

Having analysed the data presented in the table, we found out that only $45 \%$ of surgeons and $25 \%$ of oncologists were sufficiently adapted to the current life situation and had the PWB values within the normal range. A great tension of adaptive mechanisms was detected in $30 \%$ of surgeons and in $42 \%$ of oncologists. It can be concluded that they were experiencing severe stress and might have professional maladaptation. Obviously, it was interesting to compare the psychological indicators of adaptation of the examined sample and these data of the psychophysiological adaptation indicators. The latter showed that a significant share of the subjects could be experiencing this or that state of professional maladaptation.

The analysis of the indicators of situational and personal anxiety is given in Figure 1. 


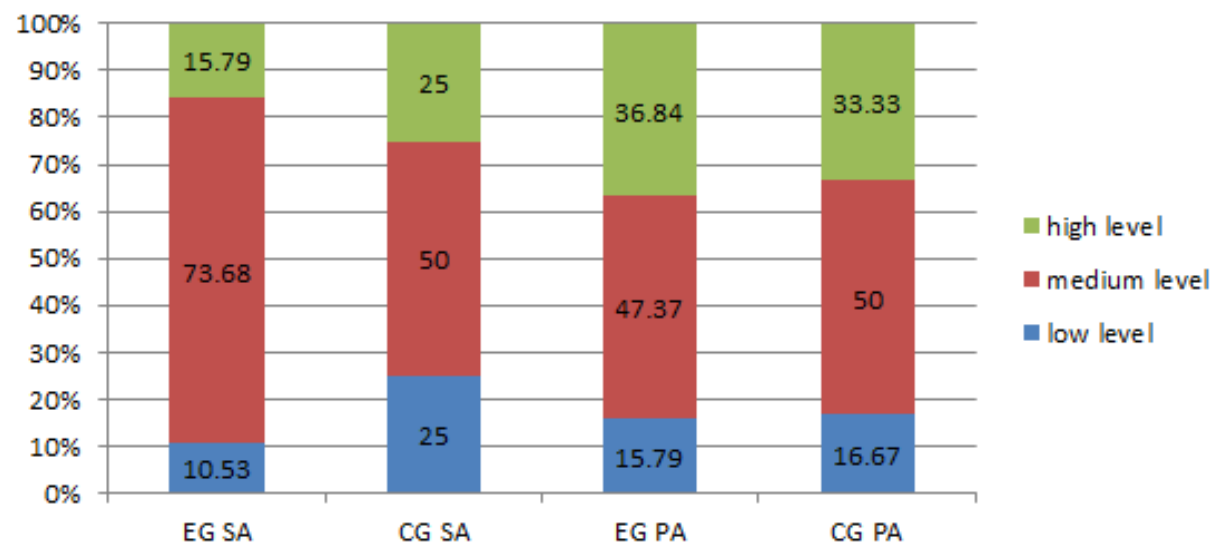

Figure 1. Distribution of situational anxiety (SA) and personal anxiety (PA) of the LROD doctors, \%. EGexperimental group, CG-control group.

The data in Figure 1 show that a quarter of the doctors in the control group had an increased level of situational anxiety, compared to only $16 \%$ in the experimental group. This suggests that the situation of the examination procedure had low subjective importance for most of the staff and was perceived quite calmly. However, more than a third (37\%) of the surgeons and $33.3 \%$ of the non-surgeons demonstrated high levels of personal anxiety, which suggests that they tend to see a threat to their self-esteem and life activities in a wide range of situations and respond to this with a very strong anxiety, especially when it comes to assessing their competence and authority. High personal anxiety directly correlates with a neurotic conflict, emotional and neurotic breakdowns, manifestations of professional maladaptation, and indicates emotional distress. Like the level of personal anxiety, the degree of chronic fatigue is an important factor that affects the current state of the functional system of the body that is responsible for adaptation. Figure 2 shows data on the severity of chronic fatigue symptoms in the examined population.

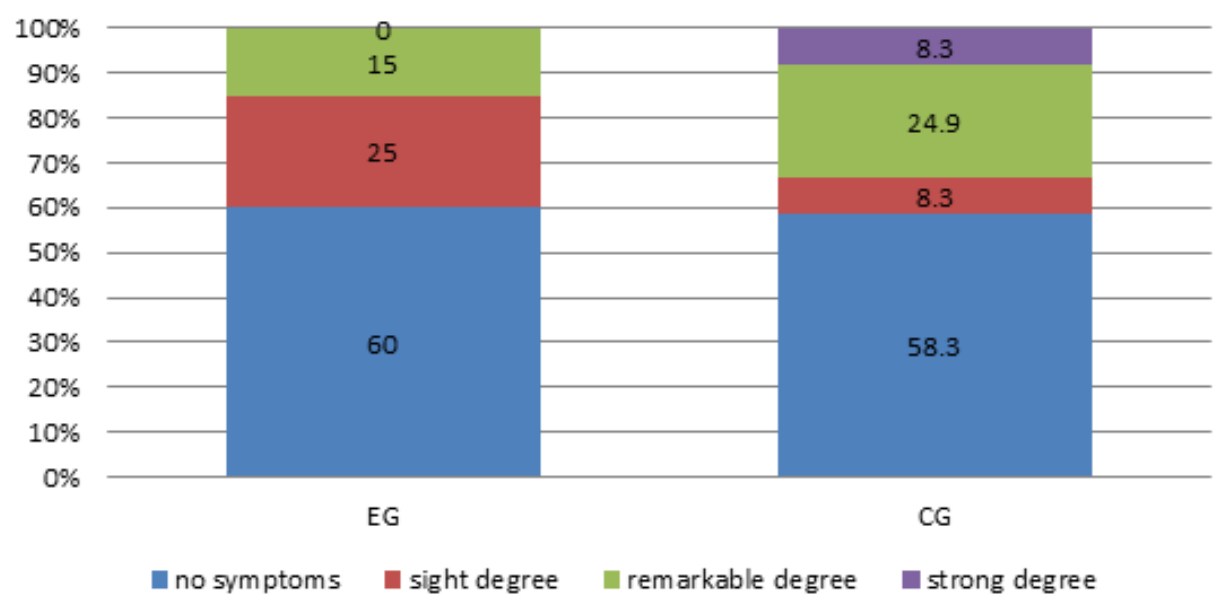

Figure 2. Comparison of chronic fatigue degrees of the oncologists, $\%$.

According to these data, the signs of chronic fatigue were detected in $40 \%$ of surgeons, and $15 \%$ of them had a remarkable degree. As for other doctors, $8.3 \%$ had a strong degree, $25 \%$ - a remarkable degree, and $8.3 \%$-a slight degree. In both groups, $40 \%-41 \%$ demonstrated certain signs of chronic fatigue. Chronic 
fatigue is followed by a steady and visible decrease in working capacity, associated with depletion of adaptive resources, which significantly reduces a person's ability to adequately resist to occupational stress. It also makes a person use his or her reserve resources, which exacerbates the effects of overstrain and exhaustion. Like any object of psychophysiological analysis, the process of adaptation and its disorders are complex, multiple-factor, and multidimensional phenomena. To fully understand the role and importance of the psychophysiological characteristics of adaptation and maladaptation, one should thoroughly analyse the relationship of its individual indicators (indices) with the data reflecting the psychological characteristics of this process. Although anxiety, chronic fatigue, and socio-psychological adaptation have been considered in numerous publications, there has been no agreement on the relationship between these phenomena and manifestations of maladaptation. The latter are connected with changes in the mobilization of the functional reserves of the physiological systems acting as the reflection of the psychophysiological mechanisms of adaptation, and, accordingly, the basic adaptive stability of the systemic reaction of the body to professional activities. Therefore, we performed the correlation analysis of this relationship among the staff of the oncological hospital. A moderate heterogeneous correlation interdependence (the Pearson chi-squared test) of the values of the functional indices and the psychological indicators of professional maladaptation was established for both surgeons and other oncologists (Table 5).

Table 5. The level of correlation (according to the Pearson chi-squared test) between the physiological indices and the psychological indicators of professional maladaptation of oncologists.

\begin{tabular}{|l|l|l|l|}
\hline \multirow{2}{*}{ Indicators } & Anxiety & PA & \multirow{2}{*}{ Chronic Fatigue Index } \\
\cline { 2 - 4 } & SA & -.243 & -.301 \\
\hline PWB & -.257 & .357 & .274 \\
\hline AP & .350 & .332 & .355 \\
\hline RI & .398 & .545 & .373 \\
\hline ES & .540 &
\end{tabular}

Note: significant coefficients $(p<0,05)$ are given in bold.

\section{DISCUSSION}

These results prove that the main functional indices are informative enough for predicting the processes of professional maladaptation among oncologists. The multilevel direct correlation between the values of AP, $\mathrm{RI}$, and PWB indices and the indicators of anxiety diagnostics according to both Spielberger and Yu. L. Hanin scales indicates that people with a reduced adaptive response to stressful factors or overstrain of adaptive capacity of the cardiovascular system more often have a stronger than moderate anxiety (the tendency manifests itself most vividly in the noticeable correlation of the PWB values and the indicators of both anxiety scales). A distinctive feature of chronic fatigue is that it builds up gradually, over a long period of time, and most often for a long time takes place without any objectively expressed manifestations. This may explain the less pronounced correlation between the indicators of physiological indices and the index of chronic fatigue. Nevertheless, distinct correlation relationships were established when analysing the correlation relationships between the indicators of anxiety and chronic fatigue. For instance, the index of chronic fatigue has a positive correlation with the level of situational anxiety of 0.62 at $P<0.01$ and with the indicators of personal anxiety of 0.68 at $P<0.01$. Apparently, stressful factors in one's professional activities upset the balance between the personality and the environment and trigger defensive reactions aimed at eliminating or levelling the contradiction. The ultimate aim is restoring the lost balance or the one that may be lost, i.e., the restoration of adaptability. The subjectively arising contradiction is expressed as a feeling of anxiety. In such a situation the tension of adaptive mechanisms of the cardiovascular system is manifested as a change in the corresponding indices of the functional state of the body. The correlation relationships among emotional 
distress (anxiety) and the tension of psychological adaptation resources (degree of chronic fatigue) with the psychophysiological indicators of professional adaptation revealed in the study allowed us to more accurately diagnose an increased risk of neurotic conflict, emotional breakdowns against the background of developing professional maladaptation of the subjects.

\section{CONCLUSION}

The obtained data indicate that socio-psychological adaptation of oncologists to professional activities depends on many factors. Psychological, social and biological factors are inextricably linked and determine the severity of maladaptation manifestations. At the same time, numerous publications devoted to occupational stress and professional maladaptation of doctors focus on psychological aspects of correction and prevention of maladaptation manifestations. For instance, it is recommended to teach oneself selfregulation skills, or it is recommended to normalize work and leisure or have training sessions (improving one's communicative skills, personal confidence, or personal development). Various tools of psychological support are being developed, primarily in the form of individual psychological counselling (Amirov et al, 2004; Bagriy, 2009; Kosarev \& Babanov, 2010; Pasechnik \& Pasieshvili, 2013; Polyakova, 2008). At the same time, as a multi-level dynamic process, adaptation is associated with a change in the work of various organs and systems of the body and determines the level of psychophysiological and mental health of a person and the general effectiveness of one's activities at the biological, mental and socio-psychological levels. Therefore, by developing and improving the methodology and assessment procedure of various levels of oncologists' adaptation to professional activities, it is possible to predict the occurrence of maladaptation and adequately address these issues not only in terms of psychological correction and prevention, but also with the measures aimed at improving the functional state of the body and, above all, its main organ systems.

\section{REFERENCES}

Alyushin, M. V., Kolobashkina, L. V. (2010). Optimal Behavior and Psychoemotional State: Textbook. Moscow: NRNU MEPhl.

Amirov, N. Kh., Berkheeva, Z. M., Garipova, R. V., Shakirova, L. V., Berkheev, I. M. (2004). Professional activity as the factor in the formation of occupational pathology among health workers. Kazan Medical Journal, 85(4), 305-307.

Bagriy, M. A. (2009). Specifics of occupational stress development in doctors of various specialties: Author's abstract of the thesis of Candidate of Psychological Sciences. Moscow.

Beznosov, S. P. (2004). Professional Deformation of Personality. St. Petersburg: Rech.

Boyko, V. V. (2008). Psychoenergetics. St. Petersburg: Peter.

Evdokimov, V. I., Marishchuk, V. L., Gubin, A. I. (2008). Emotional states in work extreme conditions and their correction. Bulletin of Psychotherapy, 26(31), 56-66.

Guido, L. A., Goulart, C. T., da Silva, R. M., Lopes, L. F., Ferreira, E. M. (2012). Stress and burnout among multidisciplinary residents. Rev. Lat. Am. Enfermagem. Nov-Dec., 20(6), 1064-1071. https://doi.org/10.1590/s0104-11692012000600008

Kosarev, V. V. Babanov, S. A. (2010). Occupational morbidity of medical workers. Medical Almanac, $3(12), 18-21$.

Larentsova, L. I. (2002). Professional stress of dentists and methods of its correction: Author's abstract of the thesis of Doctor of Medical Sciences. Moscow State University of Medicine and Dentistry. Moscow.

Leonova, A. B. (2000). Basic approaches to the study of occupational stress. Moscow State University Journal, 14(3), 4-21. 
Mordant, P., Deneuve, S., Rivera, C., Carrabin, N., Mieog, S., Malyshev, N. (2014). Quality of life of surgical oncology residents and fellows across Europe. Journal of Surgical Education,71(2), 222228. https://doi.org/10.1016/j.jsurg.2013.07.010

Nikiforov, G. S. (2006). Psychology of Occupational Health. St. Petersburg: Rech.

Pasechnik, I. P., Pasieshvili, L. M. (2013). Aspects of rehabilitation of a doctor at the patient's death. Family Medicine, 46, 130-132.

Polyakova, O. B. (2008). Mental Hygiene and Prevention of Professional Personality Deformations: Textbook. Moscow: Publishing house of Moscow Psycho-Social Institute.

Raigorodsky, D. Ya. (2010). Practical Psychodiagnostics. Methods and Tests: Textbook. Samara: Letopis.

Rybina, O. V. (2005). Psychological characteristics of doctors experiencing occupational stress: Author's abstract of the thesis of Candidate of Psychological Sciences. St.Petersburg Psychoneurological Research Institute, St. Petersburg.

Thiels, C. A., Lal, T. M., Nienow, J. M., Pasupathy, K. S., Blocker, R. C., Aho, J. M. (2015). Surgical never events and contributing human factors. Surgery, 158(2), 515-521. https://doi.org/10.1016/j.surg.2015.03.053

Tsai, Y.-C.(2012). Factors and symptoms associated with work stress and health promoting lifestyles among hospital staff: a pilot study in Taiwan. BMC Health Serv. Res., 12, 199- 219. https://doi.org/10.1186/1472-6963-12-199

Ushakov, I. B., Shalimov, P. M. (1996). Functional reliability and functional reserves of the pilot. Tomsk State University Journal. RAMS, 7, 26-31.

Wasserman, L. I., Schelkova, O. Yu. (2004). Medical Psychodiagnostics. St. Petersburg: Akademia.

World Health Report 2001: Mental Health: A New Understanding, A New Hope. (2001). World Health Organization. Geneva: WHO.

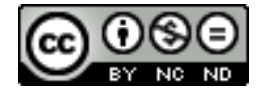

This work is licensed under a Attribution-NonCommercial-NoDerivatives 4.0 International (CC BY-NC-ND 4.0). 